\title{
Breves notas sobre el concepto de acción
}

\section{Carlos Alberto Matheus López}

"La justicia es una señora, que el que con ella canta, pronto llora»

Antiguo refrán español

\section{Nociones previas}

Realmente existen contados temas en el ámbito del Derecho Procesal Civil, en el que existan opiniones tan contrapuestas y diversas como en el concepto de acción, razón por la cual su explicación relativamente compleja y dificultosa ${ }^{1}$, ha contribuido a oscurecer el desarrollo pleno de su contenido. En tal sentido, podemos afirmar con Pekelis, que la instintiva y espontánea falta de certeza, como la unidad del uso del término acción, parece contener en sí misma la diversidad e incertidumbre de las diversas concepciones que se disputan aún en nuestros días el campo de los estudios jurídicos. ${ }^{2}$

Es por todo lo antes expresado, que algún sector de la doctrina ha preferido renunciar a la determinación de este concepto, señalando la irrelevancia práctica de la idea de acción sobre la que tanto se ha discutido, sin haberse preguntado antes en qué medida influiría en las consecuencias jurídicas el concebirla de una u otra manera, o aun tan sólo hacer referencia a ella. ${ }^{3}$

1 Jaime Guasp Delgado, La Pretensión Procesal, Editorial Civitas S.A., Madrid, 1985, p. 49; en este sentido Nicola Jaeger, Diritto Processuale Civile, Seconda edizione aggionata, Unione tipografico-editrice torinese, 1943, pp. 93-94, afirma que "pocos problemas de derecho procesal han provocado tanta abundancia de opciones y argumentaciones».

2 Alejandro Pekelis, "Acción" en Revista de Derecho Procesal, No 2, Ediar editores, B. Aires, 1948, p. 116.

3 Enrico Allorio, Problemas de Derecho Procesal, Vol. I, Trad. De Santiago Sentis Melendo, Ediciones Jurídicas Europa-América, B. Aires, 1963, p. 117; de igual modo Enrico Allorio, "Reflexiones sobre el desenvolvimiento de la ciencia procesal» en Revista de Derecho 
Ante tal opción teórica, no nos queda otra alternativa más que rechazarla pues, como bien señala Morón en relación a este concepto, «su fijación, o al menos el intento de lograrla, es tarea que el jurista no debe abandonar, porque está en juego no un concepto jurídico cualquiera sino un concepto jurídico referido a la libertad de la persona en un sistema politico democrático y de libertades». ${ }^{4}$

Por otro lado, dada tal indeterminación en la doctrina, surgió una tendencia encabezada por Calamandrei, dirigida a relativizar el concepto de acción dado que, a su parecer, las diversas teorías que todavía luchan en torno a este último concepto, encuentran su justificación histórica en el momento presente, puesto que cada una de ellas debe entenderse relativa a una de entre las diversas concepciones de las relaciones entre Estado y ciudadano, por lo que las distintas teorías no pueden considerarse, en sí mismas, ni absolutamente verdaderas ni absolutamente falsas, dado que recogen desde distintos puntos de vista diversas porciones de verdads.

Se acepta con ello «la historicidad del concepto de acción y [...] que los contenidos a los cuales viene referido no pueden ser considerados de manera independiente dada la concreta estructura de los singulares ordenamientos positivos y de las conceptualizaciones que lo acompañanm. ${ }^{6}$

Pese a lo antes señalado, a nuestro parecer, si bien es cierto que el legislador podrá modificar la regulación concreta de la acción, dándole un alcance mayor o menor, suprimiéndola o concediéndola con mayor amplitud, lo que no puede hacer jamás es modificar su concepto, ${ }^{7}$ razón por la cual no podemos aceptar de modo alguno tal relatividad conceptual.

Procesal, Ediar S.A. editores, B. Aires, 1951, p. 91, propugna el carácter estérilmente teórico de la acción.

4 Manuel Morón Palomino, Derecho Procesal Civil, Marcial Pons, Madrid, 1993, p. 134.

5 Piero Calamandrei, «Sobre la relatividad del concepto de acción» en Estudios sobre el Proceso Civil, Trad. Santiago Sentís Melendo, Editorial bibliográfica argentina, B. Aires, 1945, p. 139; en contra Allorio, Problemas [...], op.cit., p. 117, nos señala que la constatación de la relatividad de la acción no puede quedar como fin en si misma, debiendo mas bien desembocar en la convicción del carácter estérilmente teórico de este concepto.

6 Ricardo Orestano, «L'azione in generale» en Enciclopedia del Diritto, Vol. IV, Giuffrèeditore, Varese, 1959 , p. 821. Nos señala adicionalmente el autor que «solo refiriéndose a ordenamientos concretos es posible, a nuestro parecer, tratar de la acción».

7 Manuel Serra Dominguez, Estudios de Derecho Procesal, Editorial Ariel, Barcelona, 1969 , p. 123. Con tal parecer, afirma adicionalmente que uel concepto de acción debe ser 


\section{Primeros esfuerzos doctrinales}

Debemos inicialmente señalar, que en la concepción romana la acción y el derecho subjetivo son una misma cosa y precisamente en ese orden, primero la acción, y luego el derecho subjetivo, ${ }^{8}$ no existiendo por ello en esta época teoría alguna que busque explicar el alcance y contenido de la acción.

Recién con Savigny, al invertirse los términos hasta entonces aceptados desde el Derecho romano, pasando así a primer lugar el derecho subjetivo, y apareciendo sólo despues el derecho de acción," es que se inicia la tentativa de autonomizar el concepto de acción, respecto al derecho subjetivo, conceptuando este autor a la acción como el aspecto particular que todo derecho asume a consecuencia de su lesión, esto es, el derecho en estado de defensa, considerado como momento en el proceso de la vida de los derechos no como derecho por sí mismo, ${ }^{10}$ negándose así en todo momento a la acción la calidad de derecho autónomo. ${ }^{11}$

Es a mitad del siglo XIX que Windscheid, al contraponer el ordenamiento jurídico romano con aquel vigente entonces en Alemania, y deducir la incompatibilidad entre la actio romana y la klagerecht germáni$\mathrm{Ca}^{12}$ pone de relieve el error de interpretación realizado anteriormente por Savigny en relación a esta primera institución, con lo que genera la repulsa inmediata de Muther, la cual se centra esencialmente en la interpretación histórica realizada, desembocando en una concepción de la acción que aún perdura, de una u otra manera, hasta nuestros días. ${ }^{13}$

por necesidad único, y no son precisamente los avatares políticos, sino las discusiones científicas las que han complicado el problema, ocultando su aparente sencillez».

8 Juan Montero Aroca, Introducción al Derecho Jurisdiccional Peruano, Enmarce E.I.R.L., Lima, 1999, p. 131.

9 Montero, op. cit., p. 132.

10 Pekelis, op. cit., p. 141; en similar sentido Serra, op. cit., p. 124, nos indica que Savigny entiende por acción el derecho a la tutela judicial derivada de la violación de otro derecho; con igual parecer Morón, op. cit., p. 136, afirma que para Savigny la acción no es mas que el aspecto particular que todo derecho asume a consecuencia de su violación; finalmente, con el mismo criterio Montero, op. cit.,p. 132, nos señala que la acción para Savigny, es el aspecto bajo el que se nos presenta el derecho subjetivo cuando ha sido violado, constituyendo un momento del derecho subjetivo.

11 Pekelis, op. cit., p. 145.

12 Joaquín Silguero Estagnan, La tutela jurisdiccional de los intereses colectivos a través de la legitimación de los grupos, Dykinson, Madrid, 1995, pp. 60-61.

13 Serra, op. cit., pp. 124-125. 
En tal sentido, para Windscheid la actio no es la facultad de invocar tutela para un derecho sino sólo la facultad de imponer la propia facultad en vía judicial, y el ordenamiento jurídico romano no era el ordenamiento de los derechos, sino de las pretensiones judicialmente perseguibles ${ }^{14}$ $y$, en tal sentido, en Roma lo decisivo no era tener derecho sino poder accionar. ${ }^{15}$ Por ello, en cualquier caso, el derecho subjetivo y la acción siguen siendo una misma cosa, manteniéndose en el campo del derecho privado. ${ }^{16}$ De esta manera, este autor puso las bases para configurar a la acción como un poder dirigido a la obtención de tutela judicial.

Por su parte, Muther considera que el derecho y la actio son dos derechos distintos, de los cuales uno es presupuesto del otro, si bien pertenecen a diversas esferas jurídicas, puesto que uno es público y el otro privado. En tal sentido, el ejercicio de la acción supone dos derechos: el del ofendido frente al Estado para la concesión de la tutela, que viene a ser el verdadero derecho de acción; y el del Estado frente al autor de la lesión, para la eliminación de ésta, donde ambos derechos, el privado y el público, no coinciden ni en su contenido -pues uno va dirigido a la restitución y el otro al respeto material del derecho- ni en el sujeto pasivo, que en la acción es el juez, como representante de la justicia estatal, y en el derecho es el obligado. ${ }^{17}$ Corresponde así a este autor, el desarrollo de las bases para el posterior desarrollo de la autonomía de la acción, así como la consideración de su carácter público.

14 Serra, op. cit., p. 125; con tal parecer Silguero, op.cit., p. 62, nos destaca la existencia de un doble significado de la pretensión: como acto y como objeto de tutela por el derecho; siendo únicamente en este último sentido, como pretensión judicialmente perseguible, que puede concebirse a la acción.

15 Silguero, op. cit, pp. 61-62. Con tal parecer nos señala el autor, que el hecho de que los romanos hablaran de actio en ese sentido, se explica principalmente en que en Roma, el ciudadano no recibía lo, que le asignaba el derecho, sino lo que le asignaba el iudicium. Por ello, lo verdaderamente decisivo era tener a su favor, no el derecho, sino el iudicium, esto es, no el tener un derecho, sino el poder accionar; de igual modo Serra, op. cit., p. 125, afirma que para los romanos lo decisivo no era lo que decía el derecho, sino lo que señalaba el magistrado.

16 Montero, op. cit., p. 133. En este sentido, debemos observar que se puede encuadrar a Windscheid aún dentro de una perspectiva monista de la acción.

17 Serra, op. cit., pp. 125-126; con similar parecer Silguero, op. cit., p. 64, nos señala que al ser el estado el sujeto obligado de la acción, ello nos lleva a configurar el derecho y la "action como dos derechos distintos, de los cuales uno es presupuesto del otro, si bien el primero es privado y el segundo es de carácter público. 


\section{Teorías sobre el concepto de acción}

Dentro ya de la diversidad de planteamientos doctrinales en torno a la acción, y a efectos de su adecuado análisis, dividiremos en dos grupos las teorías existentes, en tanto busquen explicar la esencia misma de la acción, o traten de determinar el carácter de ésta.

\subsection{Basadas en la esencia de la acción}

Sin ánimo exegético alguno, podemos señalar las siguientes teorías:

\section{A. Acción como derecho potestativo}

Constituye mérito de Chiovenda, el desarrollo de una de las teorías más originales esbozadas en torno a la acción dentro de la doctrina procesal, basada principalmente en dos afirmaciones: 1) que la acción no es un derecho frente al Estado, sino frente al adversario, y 2) que aquella no es un derecho a una prestación, sino que es un derecho meramente potestativo, esto es, un poder jurídico de producir efectos jurídicos. ${ }^{18}$ En tal sentido, la acción es el derecho de provocar la actividad del órgano jurisdiccional frente al adversario, ${ }^{19}$ esto es, el derecho de una parte de provocar frente a otra la actuación jurisdiccional de la ley, generando en esta última no un deber sino una sujeción a los efectos jurídicos de tal actuación. ${ }^{20}$

Por otra parte, si bien reconocemos los méritos de esta teoría, ${ }^{21}$ consideramos que aquella resulta insuficiente para explicar el complejo fenómeno que la acción representa, y en tal sentido, esta no nos explica cuál es la relación del Estado con el derecho potestativo que se ejercita, ni cuál es el fundamento de la actuación de aquél en el proceso, ${ }^{22}$ lo que sumado al hecho que esta última categoría doctrinal resulta hoy casi abandona-

18 Pekelis, op. cit.,p. 157; en igual sentido, Serra, op. cit., p. 127.

19 Chiovenda, Giuseppe Principios de Derecho Procesal Civil, Vol. I, Cardenas editor y distribuidor, Mexico, 1989, p. 70 y ss; del mismo modo Serra, op. cit., p. 127.

20 Calamandrei, ob,.cit., p. 147.

21 Donde el mérito mas grande de esta teoría es el haberse basado en el concepto de poder jurídico (Pekelis, op. cit., p. 159).

22 Calamandrei, ob,.cit., pp. 147-148; de forma similar Pekelis, op. cit., pp. 157-158. 
$\mathrm{da},{ }^{23}$ nos hacen desistir definitivamente de cualquier posible adhesión a esta opción teórica.

\section{B. Acción como derecho subjetivo público}

Existe, por otro lado, un sector de la doctrina que con Rocco entiende que la acción no es un derecho potestativo, sino más bien un derecho público de obligación, esto es, un derecho que tiene por objeto una prestación de derecho público, y precisamente la prestación por parte del Estado de su actividad jurisdiccional. ${ }^{24}$ Se entiende así, que la acción es un derecho subjetivo público y, por tanto, un derecho frente al Estado, el cual a través de sus órganos jurisdiccionales realiza la prestación de tutela con que tal derecho se satisface, constituyendo un derecho totalmente distinto a los derechos subjetivos privados. ${ }^{25} \mathrm{Y}$ con tal parecer, D'onofrio considera a la acción como un derecho subjetivo público dirigido hacia el Estado con efectos hacia la contraparte, el cual como consecuencia de su naturaleza pública es irrenunciable. ${ }^{26}$

Debemos, sin embargo, señalar que la opción teórica comentada parte de la premisa, a nuestro entender errónea, de equiparar el derecho subjetivo al poder jurídico, negando la existencia autónoma de poderes jurídicos fuera del ámbito del derecho subjetivo, y olvidando que «los dos términos interfieren, coordinándose o contraponiéndose, pero no se sobreponen o se destruyen». ${ }^{27}$ Del mismo modo, si bien el derecho subjetivo público se adecúa correctamente a las relaciones de derecho público

23 Luis Diez Picazo Ponce de León; Antonio Gullón, Sistema de Derecho Civil, $5^{\circ}$ edición, Vol. I, Tecnos, Madrid, 1986, pp. 429-430. En este sentido, nos señala el autor que "en buena parte se quiere comprender bajo la rúbrica de "derechos potestativos" lo que son sólo reflejos de la capacidad general de obrar de la persona o de la autonomía privada», por lo que, uestas razones inducen a abandonar una categoría que, sin embargo, goza del favor de algún sector de la doctrina y jurisprudencias

24 Ugo Rocco, Tratado de Derecho Procesal Civil, Vol. I, Temis-De Palma, Bogota-B. Aires, 1983, p. 251 y ss.; del mismo modo Pekelis, op. cit., p. 162.

25 Andrés De la Oliva; Miguel Angel Fernández, Derecho Procesal Civil, Vol. I, $4^{\circ}$ edición, Editorial Centro de Estudios Ramón Areces S.A., Madrid, 1996, pp. 173-175.

26 Paolo D'onofrio, Lecciones de Derecho procesal Civil, Trad. José Becerra Bautista, Editorial lus, Mexico, 1945, p. 118.

27 Angelo Lener, "Potere" en Enciclopedia del Diritto, Vol. XXXIV, Giuffrè-editore, Varese, 1985, p. 636; con tal parecer Diez Picazo, op. cit.,p. 426, nos señala que «el derecho subjetivo se da dentro de una relación jurídica básica, lo que permite escindir la situación de poder de la misma y considerarla como una unidad independiente». 
que pueden existir entre Estado y ciudadano, tal término únicamente se aplica en estricto a los derechos de los que sea titular la persona frente al Estado, no así al poder de acción, el cual se ejerce no sólo frente al Estado sino también frente a los demás sujetos que participan en el proceso. ${ }^{28}$

\section{Acción como poder jurídico}

Por otro lado, una gran parte de la doctrina conceptúa correctamente a la acción como un poder jurídico, entendiendo que aquella constituye el poder atribuido a los justiciables de provocar una sentencia por parte de los tribunales. ${ }^{29} \mathrm{Y}$ con tal parecer entiende Micheli a la acción, como un poder de iniciativa, cuyo ejercicio viene dirigido contra el órgano jurisdiccional, cuyo deber institucional de impartir justicia se hace concreto precisamente por el ejercicio del poder mismo, no siendo posible vincular al ejercicio mismo de este poder, el nacimiento de un deber de conducta por parte del adversario, el cual sufre la iniciativa procesal ajena. ${ }^{30} \mathrm{De}$ igual modo, Attardi define a la acción como el poder jurídico de poner en movimiento las condiciones para una decisión de comprobación sobre la existencia de la correcta voluntad de la ley invocada por el actor, sobre la fundamentación o no de la demanda. ${ }^{31}$

Por todo lo antes señalado, consideramos que la acción,es un poder jurídico, más tal afirmación nos obliga a determinar qué entendemos por este concepto, y en tal sentido, podemos afirmar que el poder jurídico

28 En este sentido Diez Picazo, op. cit., p. 428, afirma que «la calificación debe reservarse únicamente para los derechos de que es titular la persona frente al estado o administración pública».

29 Guasp, op. cit.,p. 52. Constituyendo para el autor un poder puramente político o administrativo si se quiere.

30 Gian Antonio Micheli, Curso de Derecho Procesal Civil, Vol. I, Trad. Santiago Sentís Melendo, Ediciones Jurídicas Europa-América, B. Aires, 1970, pp. 15-21.

31 Aldo Attardi, Diritto Processuale Civile, Vol. I, Cedam, Padova, 1997, pp. 54-56. Resulta necesario señalar que el concepto antes indicado, lo entiende el autor referido principalmente para el proceso de cognición, variando ligeramente su concepto en los procesos de ejecución y cautelar, resultando la acción así en el primero, el poder de poner en movimiento las condiciones para proceder a la ejecución forzada, y en el segundo, el poder de poner en movimiento las condiciones para conseguir una medida que tutele el derecho afirmado del perjuicio que pueda verificarse por la duración del proceso. 
constituye una situación jurídica abstracta y potencial, reconocida a todos los sujetos o a determinadas categorías de sujetos en orden a la satisfacción de un interés, propio o ajeno, jurídicamente relevante. ${ }^{32}$

Debemos adicionalmente diferenciar, dentro de las diversas categorías de poderes jurídicos que existen, el derecho subjetivo, la potestad y la acción. ${ }^{33}$

El derecho subjetivo constituye una situación jurídica concreta, la cual presupone una relación entre dos o más sujetos que toma el nombre de relación jurídica y que muestra por una parte al titular (o titulares) de la situación jurídica activa, y por otra al titular (o titulares) de la situación jurídica pasiva. ${ }^{34}$

Por su parte, la potestad se encuentra circunscrita únicamente a los supuestos en que el titular se encuentre investido de autoridad, y en este sentido podemos hablar de potestad jurisdiccional dado que aquella constituye una función de la soberanía, pudiéndola oponer al poder jurídico de acción, el cual no exige a los sujetos jurídicos, el ejercicio de funciones de autoridad. ${ }^{35}$

Por último, de todo lo expuesto, al ser la acción un poder jurídico, queda evidenciado que aquella se dirige contra el Estado, en su calidad de titular de la potestad jurisdiccional, ${ }^{36}$ explicándose así que del ejercicio del

32 Temistocle Martines, Diritto Pubblico, Terza edizione riveduta e aggiornata, Giuffrèeditore, Milano, 1995, pp. 38. Señala adicionalmente el autor, que el poder es una figura jurídica subjetiva que pertenece tanto al campo del derecho privado, como al del derecho público, ubicando justamente en este segundo ámbito el poder de actuar en juicio para la tutela de los propios derechos subjetivos e intereses legítimos, con lo cual vendría a calificarse a la acción como un poder jurídico público.

33 Silguero, op. cit., pp. 70-72; de forma similar Diez Picazo, op. cit., pp. 425-426.

34 Martines, op. cit., p. 39. Observa el autor como de la abstracción del poder jurídico, entendido como una situación jurídica potencial (donde resulta una situación abstracta y potencial dado que no se encuentra ligada a un interés actual, y que necesite por ello, una especificación en el momento en el cual el sujeto pretende perseguir o realizar su interés), se pasa a la concretitud del derecho subjetivo, comprendido como una situación jurídica actual (dado que la situación jurídica deviene actual, resulta necesario que el ordenamiento reconozca en cabeza de un sujeto la titularidad de un interés y el concreto poder de tutelar y hacer valer dicho interés en frente de los otros sujetos, lo cual se sustancia en la pretensión de un sujeto, reconocida y garantizada en vía directa por el ordenamiento jurídico, a que, a efectos de la realización o de la tutela de un interés, los otros sujetos pongan en movimiento un comportamiento comisivo $\mathrm{u}$ omisivo).

35 Silguero, op. cit., p. 70.

36 Enrico Tullio Liebman, "L'azione nella teoria del processo civile» en Scritti Giuridici in Onore di Francesco Carnelutti, Vol. II, Padova, Cedam, 1950, p. 447. 
poder de acción se deriven obligaciones o cargas por parte del órgano jurisdiccional $^{37}$, pudiéndose observar que la acción constituye un poder pre-existente al proceso, ${ }^{38}$ cuya naturaleza sobrepasa el ámbito de la ciencia procesal misma, ${ }^{39}$ y se ubica en aquella área fronteriza existente entre el derecho y el proceso. ${ }^{40}$

\subsection{Basadas en el carácter de la acción}

Admitida la autonomía de la acción, la doctrina se ha inclinado a discutir si ésta posee un carácter concreto o abstracto ${ }^{41}$, observándose así dos posiciones claramente diferenciadas.

A) Teoría concreta de la acción

Para Wach, propulsor inicial de esta corriente doctrinal, la acción constituye la pretensión o derecho a la tutela jurídica, entendida como el derecho al pronunciamiento de una sentencia favorable, pre-existente a la proposición misma de la demanda judicial, dirigida contra el Estado y también frente al adversario. ${ }^{42}$

Siendo seguido en tal parecer por algunos autores, como Calamandrei, quien entiende a la acción como un derecho subjetivo autónomo y concreto, es decir, dirigido a la obtención de una sentencia favorable. ${ }^{43}$

Sin embargo, pese a lo interesante de la presente opción doctrinal, ${ }^{44}$

37 Silguero, op. cit., p. 72. Con tal parecer, ante el ejercicio de una facultad contenida en el poder de acción, como es la presentación de la demanda, se derivará por parte del órgano jurisdiccional la obligación de calificar tal demanda, admitiéndola o rechazándola, de ser el caso.

38 Liebman, op. cit., p. 444.

39 De la Oliva, op. cit., p. 174.

40 En contra Serra, op. cit., pp. 141-142, considera que debe observarse la relación entre derecho y proceso, a partir del concepto de jurisdicción; por su parte Lorca Navarrete, Antonio María Introducción al Derecho Procesal, $2^{\circ}$ edición, Madrid, Tecnos, 1991, p. 24, entiende a la acción como un hecho extraprocesal de naturaleza constitucional; y Fairen, $a b$,. cit., p. 197, lo identifica con el derecho constitucional de petición.

41 Ricardo Orestano, Azione. Diritti Soggettivi. Persone Giuridiche, Il Mulino, Bologna, 1978, p. 45; del mismo modo Zanzucchi, op. cit., pp. 52-53.

42 Azione Orestano, Diritti [...], op. cit., pp.39-40; del mismo modo Liebman, op. cit., pp. $442-443$.

43 Calamandrei, op. cit., p. 135 y ss.

44 Consideramos que la teoría concreta de la acción, si bien tiene como objetivo la admirable intención del logro de la justicia en el proceso, por lo cual le resulta inconcebible que 
no podemos adscribirnos a la teoría esbozada, puesto que concebir a la acción como el derecho a una sentencia favorable nos debería llevar a concluir, con esta misma lógica que la acción es el derecho de conceder razón aun cuando ésta no se tenga. ${ }^{45}$ Además, esta teoría no explica la existencia previa de la acción en relación al proceso. ${ }^{46}$

B) Teoría abstracta de la acción

En esta perspectiva teórica la acción viene concebida como el derecho de las partes a acudir al órgano jurisdiccional, con el correspondiente desarrollo de un proceso y la obtención de una sentencia, independientemente del contenido de esta última. ${ }^{47}$

Con tal parecer, entiende Zanzucchi que la acción posee naturaleza abstracta e ideal porque es distinta de las pretensiones y de los derechos materiales a cuya realización tiende. Es más, al prescindir de estas pretensiones resulta del todo autónoma, pues ejercitado mi derecho de acción, el juez prestará necesariamente su actividad jurisdiccional, independientemente que estime o desestime mi pretensión. ${ }^{48}$

Y, por su parte, Ortells Ramos afirma que la existencia de un derecho a la actividad jurisdiccional no puede hacerse depender, ni de que la pretensión procesal sea favorable, ni de la certeza del derecho a la tutela jurisdiccional concreta afirmada, ni de la realidad del estado de hechos al que corresponde una actuación jurisdiccional del derecho. ${ }^{49}$

Y por todo lo antes expuesto, consideramos plenamente coherente y útil la presente opción teórica, a la cual nos adherimos, pues la concep-

una parte que posea el derecho no obtenga, a su vez, una sentencia estimatoria, olvida a su vez no solo la autonomía de la acción, sino la naturaleza instrumental del proceso, y la posibilidad efectiva de la falibilidad jurisdiccional, todo lo cual no priva necesariamente de justicia al proceso en sí mismo. Y en este sentido, «la posibilidad de que en el proceso se ejerciten acciones injustas con resultados positivos, no es problema que afecte a la acción sino a la jurisdicción" (Serra, op. cit., p. 157).

45 Alessandro Levi, "La certezza del diritto in rapporto con il concetto di azione" en Scritti Giuridici in Onore di Francesco Carnelutti, Vol. I, Padova, Cedam, 1950, p. 93.

46 Con similar parecer Liebman, op. cit., pp. 443-444; del mismo modo Silguero, op. cit., p. 79.

47 Serra, op. cit., pp. 129-131.

48 Marco Tullio Zanzucchi, Diritto Processuale Civile, Vol. I, Giuffrè-editore, Varese, 1947 , p. 50.

49 Juan Montero Aroca, Manuel Ortells Ramos; Juan Gómez Colomer, Derecho Jurisdiccional, Barcelona, Bosch, 1994, p. 421. Reconociendo también los autores, el valor del contenido concreto que requiere la acción para su efectiva utilización. 
ción abstracta de la acción, entendida como un poder jurídico de provocar el ejercicio de la función jurisdiccional, con independencia del resultado mismo del proceso, ${ }^{50}$ nos entrega una noción única de la acción, y por tanto válida para todo proceso jurisdiccional, ${ }^{51}$ observándose además la clara distinción de este concepto frente al de pretensión, puesto que queda claro que la acción es un poder meramente procesal, mientras que la pretensión es una declaración de voluntad, la cual posee un obvio contenido sustancial. ${ }^{52}$

\section{Conclusiones finales}

Podemos, finalmente, como producto del análisis de las diversas concepciones propugnadas en torno a la acción, y en aras de la determinación de un concepto que busque ser no solo técnico sino también adecuado, afirmar que aquella constituye el poder jurídico de naturaleza pública reconocido a todos los sujetos de derecho, para solicitar la actuación de la potestad jurisdiccional, a través de sus órganos respectivos. ${ }^{53}$

50 Jaeger, op. cit., pp. 92-93.

51 En este sentido, el concepto de acción es único y válido para todos los campos de la actuación jurisdiccional, no pudiéndose por ello hablar de acciones particulares, tales como "acción petitoria de herencia», "acción reivindicatoria», "acción de nulidad», etc. Siendo plenamente posible hablar de pretensiones diversas, las cuales si son múltiples y específicas, mas ello no sucede con la acción, la cual es única.

52 Zanzucchi, op. cit., p. 57.

53 Debe por ello entenderse el concepto de acción contenido en el tenor del artículo $2^{\circ}$ de nuestra norma procesal, como referido en estricto al poder jurídico, a efectos de lograr la plena coherencia conceptual de la figura. 